\title{
Intensidade e individuação: Deleuze e os dois sentidos de estética
}

\author{
Intensity and individuation: \\ Deleuze and the two meanings of aesthetics
}

\section{Cíntia Vieira da Silva*}

Universidade Federal de Ouro Preto, Ouro Preto, MG, Brasil

\section{Resumo}

Este artigo aborda o conceito de intensidade na filosofia deleuziana e deleuze-guattariana, expondo alguns dos elementos trazidos de outros filósofos para compô-lo. Deleuze mobiliza a "antecipação da percepção" kantiana, a "essência singular" espinosana e, com Guattari, a "latitude das formas" das disputas escolásticas. Esses componentes, e outros tantos, delineiam o conceito de intensidade e favorecem o exercício de seu papel crucial na elaboração de uma teoria da individuação que transite da estética à política, passando pela construção de uma concepção a respeito do que significa pensar e auxilie a realizar o projeto de unificação dos dois sentidos de estética.

Palavras-chave: Intensidade. Individuação. Estética. Gênese.

* Doutora em Filosofia, e-mail: cintiavs@gmail.com 


\section{Abstract}

This article discusses the concept of intensity in Deleuze's and deleuze-guattarian philosophy, exposing some of the elements brought from other philosophers to compose it. Deleuze mobilizes Kant's "anticipation of perception", the spinozian "singular essence" and with Guattari, the "latitude of forms" of scholastic disputes. These components, and many others, outline the concept of intensity and favor the exercise of their crucial role in developing a theory of individuation that transit from aesthetics to politics, through the construction of a conception of what it means to think and assist to perform the unification project of the two meanings of aesthetics.

Keywords: Intensity. Individuation. Aesthetics. Genesis.

\section{Introdução ${ }^{1}$}

Há uma polêmica dentre os estudiosos de Deleuze que é a de saber se há ou não uma estética em Deleuze. Assim, há os partidários da posição de que em Deleuze há uma estética - que são os estudiosos que dão ênfase ao quanto o trato com produções artísticas em várias áreas, como cinema, literatura, pintura, é importante para o pensamento filosófico de Deleuze, ao quanto ele cria junto com essas produções. A partir disso, esses estudiosos defendem a ideia de que há uma estética deleuziana, de que não só Deleuze cria conceitos junto com essas produções em arte (os deleuzianos não gostam de dizer "a partir de"), como também dá, ao mesmo tempo, alguma contribuição para elas; ou seja, entende-se que Deleuze não só extrai da arte contribuições para a sua produção conceitual, mas, nesse movimento de se encontrar com produções artísticas, ele colabora em alguma medida para novas maneiras de entender ou de se aproximar dessas mesmas obras de arte.

Por exemplo, há a posição de Jacques Rancière, que afirma a existência de uma estética deleuziana que implica uma certa redefinição do termo. O termo estética e seus derivados, para Rancière, não teria seu uso restrito à designação de um regime historicamente determinado de

1 Agradeço a Patrícia Bizzotto pela transcrição da conferência que deu ocasião à escrita desse texto. 
produção e recepção das obras de arte. A estética deleuziana não seria "um saber sobre as obras, mas um modo de pensamento que se desdobra acerca delas e que as toma como testemunhos de uma questão que se refere ao sensível e à potência do pensamento que o habita antes do pensamento ${ }^{2 \prime \prime}$.

Já tive ocasião de dizer que a filosofia inteira de Deleuze pode ser tomada como uma estética. Não haveria, assim, um setor do pensamento deleuziano que seria uma estética, mas toda a sua filosofia. Ela seria uma estética não naquele sentido de uma disciplina no interior da filosofia, mas no de uma teoria da sensibilidade. No entanto, é preciso fazer algumas outras ressalvas: primeiramente, entendo estética em um sentido específico, mais ligado à aisthêsis, isto é, à sensação e à sensibilidade. Por conseguinte, um outro esclarecimento a se fazer seria o de localizar esse projeto filosófico no interior daquela ideia de uma unificação dos dois sentidos de estética.

Expondo de uma maneira resumida, o projeto filosófico de Deleuze inclui a construção de um pensamento em que a teoria da sensibilidade e a teoria da arte sejam pensadas conceitualmente juntas por meio das mesmas operações. Este projeto, portanto, inclui a ideia de partir de alguns conceitos que permitam reunificar a estética como teoria da sensibilidade, por um lado, e a vertente que se dedicaria a uma teoria da arte, por outro.

Alguns anos antes de Diferença e Repetição e Lógica do Sentido, Deleuze havia publicado um artigo chamado Platão e o simulacro, que é retomado em apêndice em Lógica do Sentido. Este último, é um livro organizado em séries - são séries de paradoxos, ao invés de capítulos - cujo final é constituído por uma série de apêndices, divididos em "simulacro na filosofia antiga" e "simulacro e modernidade"3. Quer dizer, nestes apêndices, o conceito de simulacro é mapeado em vários tempos e lugares de ocorrência. Platão e o Simulacro - retomado nesse contexto de Lógica do Sentido, dentro destes apêndices - não se coloca apenas como um artigo dedicado exclusivamente a apresentar uma interpretação da filosofia de

2 RANCIÈRE, J. Existe uma estética deleuzeana? In: ALLIEZ, E. (org.) Gilles Deleuze: uma vida filosófica. São Paulo: 34, 2000, p. 505.

3 DELEUZE, G. Lógica do Sentido. São Paulo: Perspectiva, 1998. Trad. Luiz Roberto Salinas Fortes. 
Platão. Há ali uma leitura de Platão, porém o seu maior propósito é discorrer sobre o projeto filosófico da contemporaneidade. Deleuze apresenta o que pensa ser o objeto, ou melhor, a vocação da filosofia moderna; ele diz "moderna", mas, mais precisamente, ele quer dizer "do seu tempo".

E para apontar qual é a tarefa da filosofia contemporânea, Deleuze se reporta a Nietzsche e diz que a filosofia no nosso tempo ou, naquele tempo, na década de 1960 do século XX, deveria reverter o platonismo. Por fim, esta reversão, ou subversão, do platonismo implicará não apenas na inversão literal da polaridade da primazia entre modelo e cópia, e sua consequente acepção de que é necessário restaurar alguma dignidade ao mundo das cópias e das aparências, mas, antes, Deleuze dirá, será preciso ir além e demolir por completo a possibilidade de estabelecer esta distinção entre modelo e cópia.

O elemento que teria a força para efetuar essa superação da primazia do modelo e da dualidade ao qual nos referimos seria o simulacro, que é definido nesse artigo em termos muito próximos a um certo Platão, como uma modalidade ou um tipo de imagem isenta de relação com um modelo. O simulacro se furta a qualquer relação a um modelo por não depender do critério de semelhança. É claro que, para que o simulacro assuma esse papel, seja dotado dessa força, é preciso que ele seja considerado por si mesmo, de modo independente das cópias que guardam relação de similitude com um modelo. Portanto, o valor dessas imagens simuladas, ou do simulacro, tem que ser estabelecido a partir delas mesmas e, como dirá Deleuze ulteriormente, dos efeitos que elas produzem, e não de qualquer semelhança ou dessemelhança com relação a um modelo.

Com a ideia de simulacro, o problema da relação entre arte e verdade assume uma formulação bastante distinta daquela que vigora em Hegel e seus herdeiros. A partir de uma aliança com Nietzsche, Deleuze vai ressaltar a importância de uma potência do falso. Quer dizer, ao invés de dizer que as imagens artísticas enquanto imagens-simulacro dentre outras ${ }^{4}$, envolvem uma questão sobre a verdade, Deleuze dirá que

4 Dentre outras, pois, no final das contas, tudo virá a poder se tornar simulacro em Deleuze. Nesse mundo em que se aboliu a possibilidade de qualquer modelo pensado a partir de uma identidade, de uma mesmidade e, consequentemente, de uma semelhança, tudo é imagem-simulacro, pois não há nunca uma identidade de modelo ao qual referir àquilo que aparece.

Rev. Filos., Aurora, Curitiba, v. 29, n. 46, p. 17-34, jan./abr. 2017 
a questão é muito mais sobre a intensidade da potência dos efeitos que essas imagens são capazes de produzir, bem como outras modalidades de imagens. Estou dizendo que o problema é um mesmo problema reformulado, ou, pelo menos, um problema vizinho, porque a questão da verdade é colocada, em termos de uma potência do falso e da potência dos efeitos que um determinado acontecimento produz, não só para o caso da arte como para o caso da filosofia e das ciências. Em Platão e o Simulacro Deleuze não faz menção às ciências, mas se formos a O que é a Filosofia?, escrito junto com Guattari na década de 1990, vemos essa mesma questão pensada do ponto de vista das ciências.

Pois bem, o excerto anunciado, que na edição brasileira de Lógica do Sentido está entre as páginas 265 e 266, é precisamente o trecho que me serviu de base para começar a dizer que a filosofia de Deleuze é, toda ela, uma estética e que esta estética envolve a reunificação dos seus dois sentidos. Nele, Deleuze diz:

A estética sofre de uma dualidade dilacerante. Designa de um lado a teoria da sensibilidade como forma da experiência possível; de outro, a teoria da arte como reflexão da experiência real. Para que os dois sentidos se juntem é preciso que as próprias condições da experiência em geral se tornem condições da experiência real; a obra de arte, de seu lado aparece então realmente como experimentação ${ }^{5}$.

Para encurtar um pouco o caminho de como Deleuze supõe reunir os dois sentidos de estética, apontaremos de modo muito simples o que permitirá sua unificação. A primeira e a terceira críticas kantianas, mais precisamente o sentido da estética transcendental e o sentido que aparece na terceira crítica, podem balizar a compreensão do dilaceramento. Como reunir estes dois sentidos que dilaceram a sensibilidade? Deleuze procura fazer isto por meio do conceito de intensidade. Mas qual será o papel do conceito de intensidade? De que modo este conceito, ou este elemento, poderá servir ao propósito de unificar os dois sentidos de estética?

5 DELEUZE, G. Lógica do sentido. São Paulo: Perspectiva, 1998 (4ª edição), p. 265-6. 
A preocupação de Deleuze, aquela de querer fazer com que "as próprias condições da experiência em geral se tornem condições da experiência real" ${ }^{\prime}$, quer dizer, na verdade, que é preciso estabelecer uma espécie de gênese do dado. Então, o projeto filosófico deleuziano envolverá mostrar como os elementos sensíveis se engendram para uma sensibilidade em um processo do sentir e, por outro lado, como no processo do sentir se constitui uma instância sensiente, uma instância subjetiva, ou uma subjetividade, que pode ser instável, parcial, fragmentária, ou seja, algo que sente e se constitui no sentir. Mas, também aquilo que é sentido, por sua vez, não está pronto. Portanto, não é apenas o sujeito, ou a subjetividade, que se constitui no ato de sentir e, depois, no ato de pensar, mas também aquilo que depois vai se transformar em objeto para uma sensibilidade, para um pensamento, também é engendrado, produzido e, também precisa ser constituído. E o que vai permitir mostrar como se dá esta constituição é a noção de intensidade ${ }^{7}$. Aqui, Deleuze busca em várias fontes, fazendo leituras um tanto inusitadas, um pouco distorcidas ou criativas - poderíamos dizer, conforme a nossa benevolência ou antipatia, com relação a Deleuze; podemos chamar as leituras de criativas ou de pervertidas, ou como quiserem, mas reproduções dos autores que lhe servem de fonte, isto, com certeza, elas não são. E nem pretendem ser. Então, para entender e elaborar o seu conceito de intensidade, Deleuze vai buscar em fontes medievais - Duns Scott, em primeira mão e, secundariamente, leitores dele. Com relação a Kant, Deleuze faz uma espécie de adendo ao modo como a intensidade é caracterizada na Crítica da Razão Pura. Kant diz que a intensidade é uma antecipação da percepção. Assim, em uma sensação tem-se o grau zero, quando o sujeito não está diante de percepção alguma e, portanto, ele nada sente, e tem-se o momento em que o sujeito sente ou percebe algo, mas em que este algo ainda não é para ele uma qualidade e muito menos um objeto, embora seja ele um sentir que é diferente de zero. Antes de saber se estou diante de uma cor e de qual cor, a minha sensibilidade já é movida de alguma maneira,

6 Id. Ibid.

7 A respeito do papel do 'díspar' nessa gênese do sensível, da sensibilidade e do pensamento, Cf. ORLANDI, L. B. L. "Articulação por reciprocidade de aberturas", Primeira versão, n 16. Campinas: IFCH- Unicamp, 1990. Uma nova versão do texto, intitulada "Desejo e problema: articulação por reciprocidade de aberturas" encontra-se no prelo e deve ser publicada em breve.

Rev. Filos., Aurora, Curitiba, v. 29, n. 46, p. 17-34, jan./abr. 2017 
ou ocupada de alguma maneira: isto é a intensidade como antecipação da percepção.

A intensidade é o elemento mínimo da sensibilidade. E Deleuze vai querer que este elemento mínimo seja não apenas uma antecipação da percepção, quer dizer, aquilo que ainda não é integrado como uma percepção, apesar de nos afetar como sensação. A intensidade não se reduz a antecipar a percepção, mas é bem mais o elemento que engendra a sensibilidade. Para Deleuze, é, então, este elemento que faz nascer, que deflagra, que dispara, a sensibilidade. É no acaso de um encontro que a sensibilidade é engendrada e, sob o violento impacto desse encontro, tem início a "gênese do ato de pensar no próprio pensamento". Esse elemento primordial, insensível através de um uso empírico da sensibilidade, já previamente coordenado às outras faculdades pelo senso comum, segundo o modelo da recognição, é primeiro definido por Deleuze em termos negativos: "não é uma qualidade, mas um signo. Não é um ser sensível, mas o ser do sensível. Não é o dado, mas aquilo pelo qual o dado é dado $^{8 \prime}$. Algumas páginas depois, esse elemento que leva a sensibilidade a ultrapassar os limites de um uso empírico pré-determinado é nomeado e determinado de modo positivo: "este elemento é a intensidade como pura diferença em $\mathrm{si}^{\prime \prime}$.

Acontece que, por outro lado ainda - e é esta linha que me permite dizer que toda a filosofia do Deleuze é uma estética - , existe o fato de que este elemento, que é aquilo que faz com que a sensibilidade nasça ou se produza, é também a unidade mínima de todo o Real. E, retomando as referências já mencionadas, Duns Scott, Kant e Nietzsche, e vários outros que foram por mim omitidos aqui, com todos eles, Deleuze elabora a sua concepção de intensidade, em composição também com uma certa leitura de Espinosa. Assim, Deleuze poderá entender a intensidade como essência singular. Podemos igualmente dizer o contrário, que Deleuze interpretará as essências singulares espinosanas como intensidades. Esse conceito ganha, portanto, um viés ontológico, se quiserem, ou, como prefiro dizer, ele toma um papel na individuação. Ocorre que este nome,

8 DELEUZE, G. Diferença e repetição. Rio de Janeiro: Graal, 2006 (2a edição, tradução revista), p. 203.

9 Id, p. 209. 
"teoria da individuação" - que eu prefiro àquele de "ontologia"10 em razão de Deleuze privilegiar o devir em detrimento do ser - , que diz respeito à parte mais geral, digamos assim, da filosofia, tal teoria da individuação não se separa de uma teoria da sensibilidade. As artes, para Deleuze, também serão pensadas no quadro de uma teoria da individuação, pensamento que vai se adensando em Mil platôs e O que é a filosofia? Ainda em Diferença e repetição, entretanto, já se coloca nitidamente o papel da intensidade quanto à individuação.

Deleuze contrapõe a intensidade, que constitui as "condições da experiência real", à extensão, que configura "as condições da experiência possível"11. Essa distinção entre experiência real e experiência possível não é explicada por Deleuze, embora seja crucial e se encontre no cerne do projeto de unificação dos dois sentidos de Estética. Não me parece que seja evidente por si mesma essa distinção, portanto, segue-se uma hipótese de leitura. A distinção entre "experiência real" e "experiência possível" parece retomar aquela entre o terreno dos fatos e o terreno do direito (estabelecida a partir das questões tornadas centrais pela filosofia transcendental kantiana: quid facti e quid juris). A crítica de Deleuze à distinção entre o que ocorre no terreno dos fatos, contrapondo-se ao que seria válido de direito, repousa em duas objeções. A primeira é que a suposição de algo que seria verdadeiro no terreno do direito, e contraria o que ocorre de fato, só pode se sustentar com base em uma essência ideal pressuposta, em uma "imagem do pensamento"12, para usar a expressão consagrada por Deleuze. É apenas ao erigir como modelo um certo modo de funcionamento das faculdades, com resultados previstos e procedimentos já conhecidos, que se torna possível pressupor algo como possível, ainda que contrarie o testemunho do que tem ocorrido.

10 Muito embora eu já tenha utilizado o termo "ontologia" em outros textos para falar sobre a filosofia de Deleuze, acabei preferindo abandoná-lo por avaliar que se presta mais a equívocos que a algum esclarecimento.

11 Id., p. 326.

12 Esta expressão dá nome a capítulos tanto de Proust e os signos quanto de Diferença e repetição e designa os pressupostos subjetivos e implícitos que a filosofia da representação confere a si mesma como fundamento inconfesso, enquanto estima começar do zero, em ruptura com a opinião e o senso comum. 0 resultado é a perpetuação de um vínculo da filosofia com a doxa, na medida em que se mantém a forma da opinião e do senso comum, apesar do abandono de seus conteúdos. 
A segunda objeção é que a contraposição entre fato e direito não impede que o transcendental, o âmbito das condições da experiência possível, que define aquilo que é válido de direito, seja decalcado do uso empírico das faculdades, a partir de seu uso mais rudimentar referente aos atos de recognição (rememoração ou reconhecimento do já visto). A contraposição entre fato e direito, portanto, torna-se confusa, pois os dois polos do que deveria ser uma distinção são colocados em uma relação circular de cópia e modelo. $\mathrm{O}$ transcendental, que deveria fornecer as condições para o empírico, é concebido segundo a imagem daquilo que deveria fundar. Por isso, Deleuze fala em "condições da experiência real", que devem ser estabelecidas a partir de uma perspectiva genética que mostre de que modo cada faculdade e o trabalho conjunto entre elas são produzidos por meio daquilo que força o pensamento a se colocar em movimento, que é a intensidade, a partir do momento em que engendra uma sensibilidade transcendente. $\mathrm{O}$ termo transcendente aqui não designa um ultrapassamento da experiência possível ou fenomênica, ou ainda um acesso ao âmbito das coisas em si, mas o ultrapassamento dos limites previamente atribuídos à sensibilidade, como às outras faculdades, em um uso recognitivo.

Deleuze afirma igualmente que a intensidade é "o ser do sensível". Contrapondo-se a Platão, estabelece que "é a diferença na intensidade, não a contrariedade na qualidade, que constitui o "ser" do sensível". As qualidades, assim como a extensão, são desdobramentos da intensidade tal como percebida por meio de um uso empírico (ou recognitivo) das faculdades. Um dos passos do empirismo transcendental é "uma pedagogia dos sentidos" para que se possa aprender a distorcer os sentidos de modo a "apreender a intensidade, independente do extenso ou antes da qualidade nos quais ela se desenvolve"13. A necessidade de uma pedagogia indica que a gênese ${ }^{14}$ não se confunde com uma geração espontânea, mas é produção como efeito de forças que instauram uma diferença. Além de deflagrar o uso transcendente

Id., p. 332-3.

14 Roberto Machado insiste na importância da perspectiva genética e genealógica na filosofia de Deleuze, e no papel de Espinosa na realização deste projeto. CF. MACHAD0, R. Deleuze, a arte e a filosofia. Rio de janeiro: Zahar, 2009. 
das faculdades, por exercer uma força sobre a sensibilidade obrigando-a a tornar-se capaz de apreendê-la, "a intensidade é individuante"15. Isto ocorre porque ela "se exprime imediatamente nos dinamismos espaçotemporais"16, pois é o princípio de dramatização das ideias. As ideias, como complexos de relações diferenciais indistintas e virtuais, atualizam-se e se distinguem por meio das intensidades. Há uma estrita correspondência entre "a estética das intensidades" e a "dialética das ideias" 17 , de modo que as determinações de espaço e de tempo que transcorrem no processo de atualização de diferenças virtuais são geradas pelas intensidades, e não por meio de formas a priori de espaço e de tempo. Em resumo, "a individuação é o ato da intensidade que determina as relações diferenciais a se atualizarem, de acordo com linhas de diferenciação, nas qualidades e nos extensos que ela cria"18.

Estávamos trabalhando a partir de textos como Diferença e Repetição e Lógica do Sentido, mas se pensarmos em textos posteriores, como Mil Platôs e O que é a Filosofia?, já escritos em parceria com Guattari, teremos esta concepção das artes funcionando no interior de uma teoria da individuação de modo muito mais explícito e com muito mais força. Nesse contexto, temos ainda mais elementos para defender a ideia de chamar a filosofia deleuziana de uma estética, entendendo isso como um modo de conferir primazia ao sensível, e não como maneira de dar importância a uma disciplina filosófica em detrimento de todas as outras, e muito menos de restaurar um regime de apreciação e criação da arte que privilegia as noções de obra, de autor e confere importância a cânones e valores que funcionam de modo normativo.

É que a individuação concerne ao pensamento tanto quanto ao surgimento de diferenças no que poderíamos chamar, sob os auspícios de Espinosa, de Natureza. O âmbito dos corpos experimenta individuações que não diferem substancialmente do campo das produções de pensamento. Em Mil platôs, encontramos as intensidades operando novamente em uma teoria da individuação. Em "1730 - Devir-intenso,

\footnotetext{
${ }^{15}$ DELEUZE, G. Diferença e repetição, p. 345.

16 Id., p. 345.

17 Id., p. 344.

18 Id., p. 346.
} 
devir-animal, devir-imperceptível...", platô cujo título já anuncia a temática da individuação, o conceito de intensidade é engrenagem em uma máquina de individuação nitidamente espisonista, que conecta velocidades e lentidões, movimento e repouso aos afectos e ao desejo. É digno de nota que grande parte dos casos de individuação não subjetiva, nomeados por Deleuze e Guattari como “hecceidades”, são, em sua maioria, obras de arte. Literatura, música, pintura, e algumas rápidas alusões ao cinema, são convocados para compor a trama conceitual que permite pensar as individuações como devires.

Ora, "hecceidades" e "intensidade" são colocadas como equivalentes: "um grau, uma intensidade, é um indivíduo, Hecceidade, que se compõe com outros graus, outras intensidades para formar um outro indivíduo"19. O grau de uma qualidade, como o calor, que é o caso mencionado por Deleuze e Guattari, tem uma individualidade que não se confunde com a da substância ou do sujeito que ela qualifica. Para explicar esta distinção, Deleuze e Guattari recorrem ao sétimo volume da extensa obra de Pierre Duhem, intitulada Le système du monde, valendo-se da distinção entre formas substanciais e formas acidentais. Estas últimas dizem respeito às qualidades acidentais, ou seja, àquelas que se aplicam a uma substância ou sujeito sem integrarem sua essência. Qualidades tais como a caridade, a brancura ou o calor (os exemplos são de Deleuze e Guattari, com exceção da caridade, que retomam os exemplos medievais recolhidos por Pierre Duhem) comportam mais e menos, contudo, mesmo sendo quantificáveis, não são partes mensuráveis em termos de extensão. Nas palavras dos autores, "um dia mais curto ou um dia mais longo não são extensões propriamente ditas, mas graus próprios da extensão como há graus próprios do calor, da cor etc ${ }^{\prime 20}$.

Para explicar melhor a formulação do conceito de intensidade em Mil platôs, retomemos o texto de Pierre Duhem. O debate em torno da latitude das formas ocupa dois capítulos do sétimo volume de sua obra e o que nos interessa mais diretamente começa a ser exposto a partir da distinção aristotélica entre quantidade e qualidade. Mesmo que haja

19 DELEUZE, G \& GUATTARI, F. Mil platôs: capitalismo e esquizofrenia, v. 4. São Paulo: 34, 1997, p.38. Tradução de Suley Rolnik.

20 DELEUZE, G \& GUATTARI, F. Mil platôs: capitalismo e esquizofrenia, v. 4. São Paulo : 34, 1997, p.38. Tradução de Suley Rolnik. 
uma distinção entre qualidades descontínuas (como o número) e contínuas (como o comprimento, a superfície e o volume), os dois tipos de quantidade têm em comum o crescimento por adição de unidades (no caso das descontínuas) ou de partes (no caso das contínuas) "homogêneas umas às outras" 21 . $\mathrm{O}$ mesmo não ocorre com a qualidade. Uma "forma qualitativa" pode ter graus mais intensos ou mais atenuados, constituindo sua intensio e sua remissio. Tomando como exemplo graus de calor, temos que um calor mais intenso não é apenas um calor com maior número de partes ou unidades do que as de um calor mais atenuado. Como explica Duhem:

[...] cada calor de uma dada intensidade é um calor de uma espécie determinada e esta espécie é distinta da espécie a que pertence todo calor de uma outra intensidade; um calor atenuado não pode ser visto como uma parte de um calor mais intenso; todo calor de dada intensidade é algo de essencialmente indivisível ${ }^{22}$.

O problema da intensione et remissione formarum (intensificação e atenuação das formas), relativo à Física moderna, beneficiou-se de discussões teológicas medievais, tais como a empreendida por Pedro Lombardo em seu primeiro livro de Sentenças em torno da caridade, suscetível a variações gradativas em um mesmo ser humano ao longo de sua existência. Em seu comentário a este texto, Tomás de Aquino entende que a intensificação de uma qualidade é um progressivo aperfeiçoamento ou acabamento (aproximação em relação ao télos). Duhem explica:

Uma forma acidental, uma qualidade não tem, então, por essência, nem intensio nem remissio; se essas palavras podem ser empregadas, é apenas quando se fala das relações entre esta forma e o sujeito que ela afeta...23

21 DUHEM, P. Le système du monde. Paris: Hermann, 1956, t. VII, p. 481. As traduções deste texto são todas feitas pela autora.

22 Id. Ibid.

23 Id., p. 483. 
Ainda comentando Tomás de Aquino, Duhem exemplifica: "não se pode dizer de uma brancura que ela é mais ou menos brancura, mas antes de um corpo que ele é mais ou menos branco ${ }^{24 \prime \prime}$.

Um corpo que se torna mais branco ou mais quente aperfeiçoou sua participação em uma mesma forma acidental, e não adquiriu uma nova forma. O sentido desta participação se torna mais claro se pensarmos na forma acidental da caridade, em lugar da brancura ou do calor. Uma alma mais caridosa é aquela que se dispôs a receber de Deus o dom de participar de modo mais perfeito desta qualidade, por meio de uma união com Deus. Em função de todas as ressonâncias teológicas desta concepção que envolve o conceito de participação, Deleuze e Guattari, apesar de exporem esse lado da questão, desviam do tema para dar ênfase à individualidade própria desses graus de uma mesma qualidade.

Para distinguir as formas acidentais das formas substanciais, das quais um sujeito (ou objeto) participa ou não, sem possibilidade de variação gradativa, a escolástica cria o termo latitude (latitudo). Para melhor definir a noção de latitude, Duhem recorre à Suma de Lógica, um opúsculo inicialmente atribuído a Tomás de Aquino, que os estudiosos verificaram posteriormente ter sido escrito em época posterior. Dentre os componentes deste texto a que Duhem recorre para conferir mais nitidez ao conceito de latitude está a distinção entre intensio e extensio. A intensio designa o grau de perfeição de uma forma, ao passo que a extensio indica a grandeza do sujeito em que a forma se efetua. Assim, não se deve confundir a brancura mais ou menos intensa de um objeto - que seria do âmbito da intensio - com um objeto branco maior ou menor - o que seria referente à extensio. A latitudo se opõe à extensio. Vemos que é bem neste sentido que Deleuze e Guattari se apropriam dos termos intensio e latitudo em Mil platôs, mantendo-os em latim em vários momentos, aliás. Além disso, a intensio como âmbito para pensar o grau de perfeição das formas é o elemento utilizado por Deleuze para interpretar, ainda em Spinoza et le problème de l'expression, de 1968, a essência singular espinosana como intensidade, na medida em que a essência singular dos

24 Id., p. 484. 
modos é também um grau de perfeição definida com relação à perfeição absoluta da substância.

Posteriormente, há um acréscimo no que se refere à explicação do processo de intensificação das formas. Esta nova elaboração coloca em jogo a noção de partes que não são extensas, que Deleuze nomeará diretamente como partes intensivas ${ }^{25}$ e utilizará na sua compreensão da teoria espinosana da individuação. Conforme Henri de Gand,

o aumento das formas não se faz por uma aposição de partes em sua substância ou em sua essência; é um acréscimo de força (in virtute), graças ao qual a forma aumentada se torna mais eficaz em sua própria operação, o que não poderia produzir a adição do semelhante a seu semelhante; uma mornidão somada a outra igual não perfaz um calor maior ${ }^{26}$.

É plausível supor que esta concepção da intensificação como aumento de força tenha caído no gosto filosófico de Deleuze e Guattari, o que é mais perceptível no caso de Deleuze, que privilegia o conceito de força pelo menos desde Nietzsche e a filosofia (1962). O conceito de força tem igualmente grande importância em Lógica da sensação (1969) e O que é a filosofia? (1991), colocando-se como o que é dado a sentir e perceber pela produção artística. $\mathrm{O}$ procedimento utilizado pelos autores aqui, no entanto, como em muitos outros casos, é o de se servir dos componentes que avaliam ser pertinentes à sua própria elaboração, deixando de lado aspectos que lhes parecem estranhos a seu próprio campo conceitual. Assim, descartam a linha da concepção de Henri de Gand segundo a qual a intensificação de uma qualidade pode ser compreendida como uma passagem da potência ao ato, em função do privilégio que conferem (e que já está presente nos textos de Deleuze anteriores ao seu encontro com Guattari) ao par virtual-atual, em detrimento, e até mesmo em substituição, ao par potência-ato.

Outro elemento aproveitado por Deleuze vem de um pensador que se contrapõe à concepção de Henri de Gand, bastante aristotélica e

25 Para uma apresentação detalhada do papel do conceito de intensidade na leitura deleuziana da teoria espinosana da individuação, permito-me indicar meu artigo SILVA, Cíntia Vieira da. Da física do intensivo a uma estética do intensivo: Deleuze e a essência singular em Espinosa. Cadernos Espinosanos, n 22, 2010, pp. $37-53$.

26 Pensador medieval citado por DUHEM, P. Op. cit., p. 487. 
tomista, que foi discípulo de Duns Scoto, tão importante na elaboração da univocidade do ser, presente em Diferença e repetição. Jean de Bassols, o referido discípulo, defende a existência de duas espécies de quantidade: a quantidade de massa, ou descontínua, e a quantidade de perfeição na essência, ou de força na ação. Ora, como força e perfeição são colocadas no âmbito da intensidade, Deleuze chamará este segundo tipo de quantidade de quantidade intensiva, que designa as variações gradativas de uma qualidade. Na apresentação desta concepção, aparece uma expressão que será muito explorada por Deleuze e Guattari no platô dos devires, em Mil platôs. O grau de uma qualidade (os exemplos são, mais uma vez, a caridade e o calor) é considerado como um indivíduo, que é mais ou menos perfeito conforme este grau seja mais intenso. Ao expor a concepção de Jean de Bassols, Pierre Duhem afirma que cada grau de calor é uma intensidade e constitui "um indivíduo da mesma forma específica que nomeamos calor" 27 e sua individualidade é apresentada como independente do sujeito portador desse grau de calor. Em Mil platôs, Deleuze e Guattari escrevem que "um grau de calor é um calor perfeitamente individuado que não se confunde com a substância ou com o sujeito que o recebe" 28 .

As intensidades são, portanto, individualidades, que podem se compor produzindo novas individuações. E os devires são processos de extração de intensidades. Deleuze e Guattari afirmam que

devir é, a partir das formas que se tem, do sujeito que se é, extrair partículas, entre as quais instauramos relações de movimento e repouso, de velocidade e lentidão, as mais próximas daquilo que estamos em vias de nos tornarmos, e através das quais nos tornamos ${ }^{29}$.

As relações de movimento e repouso, de velocidade e lentidão são, precisamente, intensidades, pois são graus ou quantidades intensivas. Outro componente dessa relação de forças conceituais do platô dos devires interessa sobremaneira ao que se procura expor no presente texto porque

27 Id., p. 508. Tradução modificada, pois nela consta "que a recebe". Mas o sujeito não recebe a substância, mas sim a qualidade do calor (mas chaleur é uma palavra feminina em francês).

28 DELEUZE, G \& GUATTARI, F. Mil platôs, v. 4, 38.

29 Id., p. 64. 
aproxima a concepção de individuação desenvolvida em Mil platôs daquela presente em Diferença e repetição, que retomamos no início do texto.

É que os devires ocorrem aquém ou além do limiar de percepção, guardando, portanto, uma "relação essencial com o imperceptível"30. O que percebemos em relação ao movimento, poderíamos dizer, segundo o vocabulário de Diferença e repetição, no uso empírico da sensibilidade, conduzido segundo o modelo da recognição, é a "translação de um móvel ou o desenvolvimento de uma forma"31. Em Mil platôs, a contraposição não se dá mais entre o modelo da recognição e um pensamento sem imagem; mas entre um "plano de organização e de desenvolvimento" que atua no sentido de dar "a sujeitos perceptivos formas a serem percebidas", e um "plano de imanência ou de consistência". No plano de imanência, o imperceptível torna-se "percipiendum" e o movimento deixa de ser imperceptível para se tornar o que "'deve' ser percebido, e só pode ser percebido"32, confirmando a compreensão do devir como pertencente à perspectiva do intensivo, uma vez que a intensidade é, a um só tempo, o que não pode ser sentido (no uso empírico) e o que só pode ser sentido e o que há para ser sentido, no uso disjuntivo ou transcendente das faculdades.

Se nos deslocarmos para o capítulo "Percepto, afecto e conceito", de O que é a filosofia?", veremos o pensamento em arte como produtor de modos intensivos do sentir e do perceber, na medida em que os afectos e perceptos produzidos nas artes são devires. Nas palavras de Deleuze e Guattari, "os afectos são precisamente estes devires não humanos do homem, como os perceptos (entre eles a cidade) são as paisagens não humanas da natureza" $a^{\prime 33}$. Tais devires, por serem intensidades, têm uma individualidade própria que não se confunde com a de sujeitos, objetos ou formas: “as sensações, perceptos e afectos, são seres que valem por si mesmos e excedem qualquer vivido [...]. A obra de arte é um ser de sensação, e nada mais: ela existe em si" ${ }^{\prime 34}$. Esses seres de sensação são diferenças (ou variedades) que surgem por meio da produção artística, o que atesta que a arte

30 Id., p. 74.

31 Id. Ibid.

32 Id., p. 75.

33 DELEUZE, G \& GUATTARI, F. O queéa filosofia? São Paulo, 34, 1992, p. 220. Tradução de Bento Prado Jr. E Alberto Alonso Muñoz. 34 Id., p. 213. 
não procura representar ou imitar seres existentes em um mundo prévio a ela, como já se poderia inferir do emprego do termo "devir": "o artista acrescenta sempre novas variedades ao mundo. Os seres de sensação são variedades $[\ldots]^{\prime \prime} 35$.

A recusa de uma concepção mimética da arte já era fortemente colocada em Mil platôs, em conexão com o delineamento do conceito de devir. Conforme escrevem Deleuze e Guattari:

Nenhuma arte é imitativa, não pode ser imitativa ou figurativa: suponhamos que um pintor 'represente' um pássaro; de fato, é um devir-pássaro que só pode acontecer à medida que o próprio pássaro esteja em vias de devir outra coisa, pura linha e pura cor. [...] Só se imita, portanto, caso se fracasse, quando se fracassa ${ }^{36}$.

A esses devires conservados na arte, Deleuze e Guattari dão o nome de monumentos. Esses monumentos não são meramente rememorativos, mas atualizam acontecimentos, que ganham uma implicação política, na medida em que podem produzir uma crença em um mundo a ser produzido por meio das novas conexões que instaura entre os viventes no mundo existente. Uma citação um pouco longa permitirá ao menos apontar a ligação entre monumento e revolução:

Um monumento não comemora, não celebra algo que se passou, mas transmite para o futuro as sensações persistentes que encarnam o acontecimento: o sofrimento sempre renovado dos homens, seu protesto recriado, sua luta sempre retomada. Tudo seria vão porque o sofrimento é eterno, e as revoluções não sobrevivem à sua vitória? Mas o sucesso de uma revolução só reside nela mesma, precisamente nas vibrações, nos enlaces, nas aberturas que deu aos homens no momento em que se fazia, e que compõem em si um monumento sempre em devir, como esses túmulos aos quais cada novo viajante acrescenta uma pedra. A vitória de uma revolução é imanente, e consiste nos novos liames que instaura entre os homens, mesmo se estes não duram mais que sua matéria em fusão e dão lugar rapidamente à divisão, à traição ${ }^{37}$.

Id., p. 227.

36 DELEUZE, G \& GUATTARI, F. Mil platôs, v. 4, p. 106-7.

37 DELEUZE, G \& GUATTARI, F. 0 que é a filosofia?, p. 229. 
Aqui, poderíamos iniciar um percurso que nos levaria a ver o quanto a produção de novas maneiras de sentir e perceber, e, portanto, de pensar, têm lugar em um combate político. Uma política dos afectos e perceptos, e dos conceitos, pode produzir novas maneiras de viver e de estar junto. Deixemos, contudo, essa linha apenas indicada para ser disparada como flecha em outro texto.

\section{Referências}

DELEUZE, G. Lógica do Sentido. Trad. Luiz Roberto Salinas Fortes. São Paulo: Perspectiva, 1998.

DELEUZE, G. Diferença e repetição. $2^{a}$ edição, tradução revista. Rio de Janeiro, Graal, 2006.

DELEUZE, G \& GUATTARI, F. Mil platôs: capitalismo e esquizofrenia, v. 4. Tradução de Suley Rolnik. São Paulo: 34, 1997.

DELEUZE, G. O que é a filosofia? Trad. Bento Prado Jr. e Alberto Alonso Muñoz. São Paulo: 34, 1992.

DUHEM, P. Le système du monde. Paris: Hermann, 1956, t. VII.

MACHADO, R. Deleuze, a arte e a filosofia. Rio de janeiro: Zahar, 2009.

ORLANDI, L. B. L. "Desejo e Problema”: Articulação por reciprocidade de aberturas. Histórias e Perspectivas, Uberlândia, p. 159-186, jul./dez. 1990.

RANCIÈRE, J. Existe uma estética deleuzeana? In: ALLIEZ, E. (org.) Gilles Deleuze: uma vida filosófica. São Paulo: 34, 2000.

SILVA, Cíntia Vieira da. Da física do intensivo a uma estética do intensivo: Deleuze e a essência singular em Espinosa. Cadernos Espinosanos, n. 22, 2010, pp. 37-53.

Recebido: 14/11/2016

Received: $11 / 14 / 2016$

Aprovado: $13 / 01 / 2016$

Approved: 01/13/2016 